\title{
Integrative role of the histaminergic system in feeding and taste perception
}

\author{
Tomoko Ishizuka ${ }^{1 *}$ and Atsushi Yamatodani ${ }^{2}$ \\ Department of Pharmacology, Osaka Dental University, Osaka, Japan \\ ${ }^{2}$ Faculty of Medicine, Department of Medical Science and Technology, Graduate School of Allied Health Sciences, Osaka University, Osaka, Japan
}

\section{Edited by: \\ Maria B. Passani, Universita' di \\ Firenze, Italy}

Reviewed by:

Fernando Torrealba, Pontificia Universidad Catolica de Chile, Chile

Roberto Coccurello, National

Research Council, Italy

${ }^{*}$ Correspondence:

Tomoko Ishizuka, Department of Pharmacology, Osaka Dental

University, 8-1 Kuzuhahanazono-cho, Hirakata 573-1121, Osaka, Japan

e-mail: ishizuka@cc.osaka-dent.ac.jp
Feeding behavior is regulated by a complex interplay of many endogenous substances, such as peptides and neurotransmitters in the central nervous system. Histamine is a neurotransmitter which expresses an anorectic effect on food intake via histamine $\mathrm{H}_{1}$ receptors. The histaminergic system exists downstream of leptin, a satiety factor secreted from white adipose tissue. Because direct stimulation of the histaminergic system by histamine $\mathrm{H}_{3}$-inverse agonists or antagonists can normalize the obese phenotype in which animal models with exogenous leptin resistance, which resembles human obesity, the potential roles of histamine $\mathrm{H}_{3}$ receptors as a therapeutic target now draw attention. Histaminergic activity is enhanced during feeding, and an oral somatic sensation is thought to affect histaminergic activity while blood glucose levels do not. In addition, gustatory information can modulate histaminergic activity by two mechanisms: by physiological excitation of the chorda tympani nerve, one of the taste nerves and by emotions elicited by taste perception, i.e., taste palatability. Particularly, aversive and hazardous taste stimuli tonically facilitate histaminergic activity, suggesting that the histaminergic system is involved in the response to harmful stimuli. Together with recent findings, it is postulated that the histaminergic system responds to both mechanical and chemical sensory input from the oral cavity during feeding and is exerted as a part of the danger response system.

Keywords: histamine, feeding, taste, palatability, hypothalamus, microdialysis

\section{OVERVIEW OF THE ROLE OF THE HISTAMINERGIC SYSTEM IN THE CONTROL OF FEEDING}

Obesity is a prevalent condition which is associated with an increased risk of a consequence of the morbidities of diabetes mellitus, hypertension, and heart disease whose incidence increases with body-mass index (BMI, body-mass in $\mathrm{kg} / \mathrm{square}$ of the height in meters). Obesity rates is in Europe and North America traditionally high, however, Asian countries such as Japan have recently reported increasing prevalences of obesity, which may reflect changes in dietary patterns and lifestyles. It is considered that life expectancy is maximal when BMI is the ideal level and is reduced $20 \%$ or more above the ideal. Thus, controlling food intake and body weight now gathers attention to overcome this worldwide health crisis induced by obesity.

Food intake is necessary for all living organisms to acquire nutrients and energy for the body to grow and repair; it is vital to the survival of every living animal and is subject to intense regulation by brain homeostatic systems (Saper et al., 2002). To ensure feeding behavior takes a high priority in brain function, mammalian brains have evolved several prominent and interrelated neuronal systems that control feeding.

Histamine is regarded as a neurotransmitter and is widely distributed in the mammalian central nervous system (Panula et al., 1984; Watanabe et al., 1984). Histaminergic neurons are confined to the tuberomammillary nucleus (TM), a small region of the posterior hypothalamus. They have wide-spread projection patterns to many different areas with their fibers being found in almost all parts of the brain (Inagaki et al., 1988). The highest density of histaminergic fibers is found in the hypothalamus (Inagaki et al., 1988), which is a brain structure known to play a crucial role in the central regulation of feeding behavior (Oomura et al., 1967).

Because of these morphological features, the involvement of the histaminergic system in the regulation of feeding behavior has been well investigated using histamine-related compounds. It was found that histamine injected intracerebroventricularly produces a long-term suppression of feeding activity in cats (Clineschmidt and Lotti, 1973). Similarly in rats, the administration of histamine into the suprachiasmatic nucleus (Itowi et al., 1988) and an acute injection of histamine in the lateral ventricle (Lecklin et al., 1998) also decreased food intake. The administration of metoprine, which elevates brain histamine content by blocking the conversion of histamine to tele-methylhistamine, a methylated metabolite of histamine, can also reduce food intake (Lecklin et al., 1995, 1998; Lecklin and Tuomisto, 1998). Conversely, when neuronal histamine is reduced by $\alpha$-fluromethylhistidine (FMH), a histamine synthesis inhibitor (Watanabe et al., 1990), significant increases in feeding behavior were produced (Orthen-Gambill 
and Salomon, 1992; Ookuma et al., 1993; Tuomisto et al., 1994). Peripheral histamine cannot cross the blood brain barrier, however, L-histidine, a histamine precursor, can and is converted to histamine, resulting in elevated central histamine levels. Studies in rats have shown that peripheral administration of L-histidine by intraperitoneal injection also suppresses food intake (Sheiner et al., 1985; Orthen-Gambill, 1988; Vaziri et al., 1997; Yoshimatsu et al., 2002). The suppressive effect of histidine is attenuated by pretreatment with FMH (Vaziri et al., 1997; Yoshimatsu et al., 2002). Thus, these findings indicate an inverse relationship between histaminergic activity and feeding.

Brain histamine appears to suppress food intake via histamine $\mathrm{H}_{1}$ receptors. Centrally administered histamine $\mathrm{H}_{1}$ receptor agonists suppressed food consumption in rats (Lecklin et al., 1998), whereas injection of an $\mathrm{H}_{1}$-antagonist into the third cerebral ventricle elicited food intake (Sakata et al., 1988). Both $\mathrm{H}_{2}$-agonists (Lecklin et al., 1998) and antagonists (Sakata et al., 1988) centrally injected had no effect on food intake. Therefore, histamine has been associated with food intake suppression via histamine $\mathrm{H}_{1}$ receptors, not via histamine $\mathrm{H}_{2}$ receptors.

Clinically, some antidepressants (Kalucy, 1980; Russ and Ackerman, 1988) and atypical antipsychotics (Deng et al., 2010), which have a high affinity for $\mathrm{H}_{1}$ receptors, increase food intake and body weight in humans. Similarly, in experimental animal models, tricyclic antidepressants which potently block $\mathrm{H}_{1}$ receptors, such as doxepin (Orthen-Gambill, 1988) and amitriptyline (Ookuma et al., 1990), can increase food intake, whereas an injection of desipramine, which has a negligible $\mathrm{H}_{1}$-blockade effect, does not affect food intake (Orthen-Gambill and Salomon, 1990). Recently, the administration of atypical antipsychotics has been shown to be associated with the emergence of metabolic derangements, including body weight increase, dyslipidemia, and type II diabetes (Coccurello and Moles, 2010). Since the orexigenic atypical antipsychotics potently and selectively stimulated hypothalamic AMP-kinase and an action was abolished in $\mathrm{H}_{1}$ receptor knockout mice (Kim et al., 2007), blockade of $\mathrm{H}_{1}$ receptors is an important candidate, despite the multiple mechanisms underlying these side effects.

\section{HISTAMINERGIC ACTIVITY DURING FEEDING}

How is the actual histaminergic activity during feeding? In order to answer this question, we observed hypothalamic histamine release during feeding by brain microdialysis. Rats were trained to consume standard chow for $1 \mathrm{~h}$ a day, and apart from this period, were not given chow but had free access to distilled water. Training was continued for minimum seven consecutive days. In this study using a brain microdialysis technique to measure extracellular histamine levels in the anterior hypothalamus, it was demonstrated that a transient and significant increase in histamine concentration was produced when rats were fed for $1 \mathrm{~h}$, while no significant change in histamine release was observed in the non-fed group, which was similarly trained but was not given chow on the day of microdialysis (Figure 1). Another research group also showed similar results when they observed hypothalamic histamine release during feeding in $24 \mathrm{~h}$-fasted rats (Itoh et al., 1991). Valdés et al. (2010) showed histamine release in the posterior hypothalamic area when hungry rats were trying

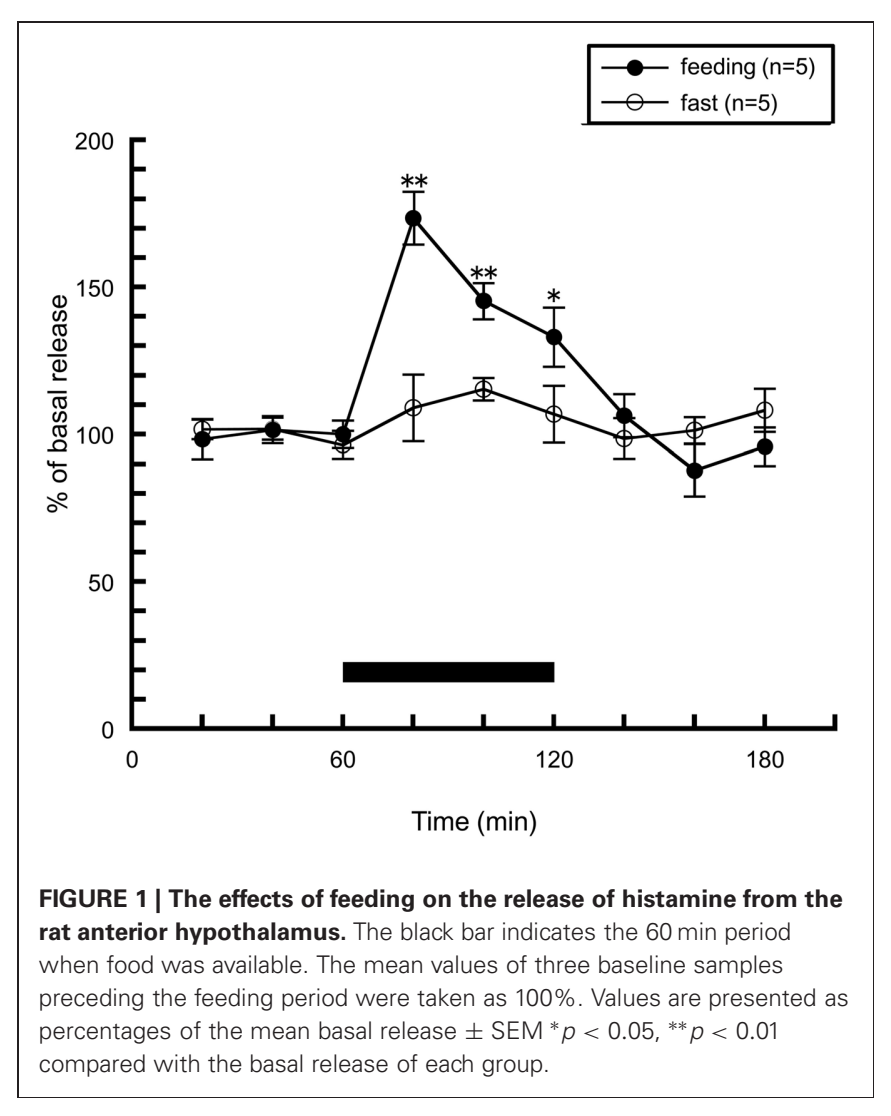

to open a mesh container filled with food. They concluded that histaminergic activation is observed during the appetitive phase of feeding behavior. In contrast, in our experiment histamine release was not altered in the non-fed group, which anticipated meal, but had no access to food on the experimental day. These different experimental conditions seem to cause the different results.

Together with these observations, it is obvious that histaminergic activity increases during feeding, but what is the factor(s) which affects histaminergic activity during feeding? One possibility is the elevation of blood glucose levels by the post-ingestive effect, thus we studied the effect of the change of blood glucose levels on histamine release. An intraperitoneal injection of D-glucose significantly elevated glucose levels by $140 \%$ from basal levels, whereas insulin lowered it to $50 \%$ of basal levels about $40 \mathrm{~min}$ after the injection (Figure 2A). However, histamine release in both groups was unaffected by the change in blood glucose levels (Figure 2B), suggesting that the activity of the histaminergic system is not altered by blood glucose levels.

Next, we investigated whether sensory information derived from food influences histaminergic activity. The hardness of food is one of the important physical properties of food, and elicits a somatic sensation received by the masticatory muscle spindles and the periodontal mechanoreceptors in the oral cavity. This information is conveyed to the brain via peripheral sensory receptors, and is thought to play an important role in the regulation of feeding behavior. We examined the effect of the hardness of food 
A

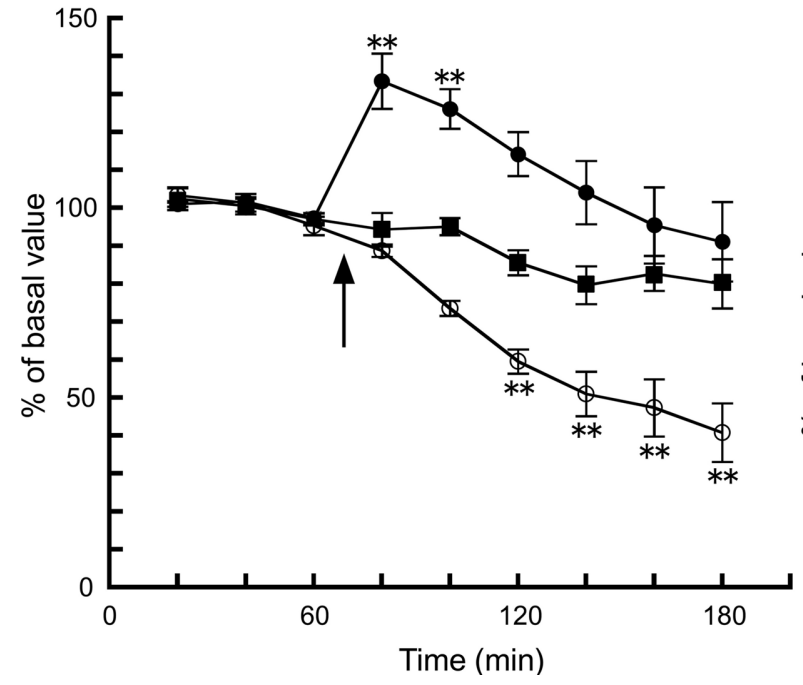

FIGURE 2 | The effects of a $5 \%$ D-glucose $(n=6)$ or $200 \mathrm{mU}$ insulin $(n=6)$ injection on (A) blood glucose levels and (B) hypothalamic histamine release in urethane-anesthetized rats. The arrow indicates the time point of injection of each compound. The mean values of
B

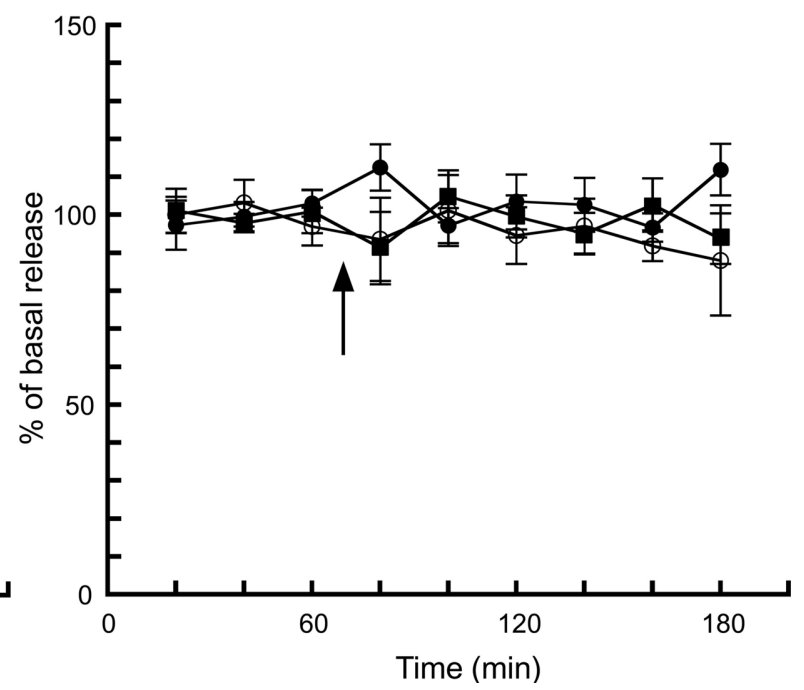

three baseline samples preceding the injection were taken at $100 \%$. Values are presented as percentages of the mean basal values $\pm \mathrm{SEM}^{* *} p<0.01$ compared with the basal values of each group. on histamine release when rats consumed either of two types of pellets: hard and soft pellets. Hard pellets had similar amounts of tensile stress to commercial pellets but were composed of different ingredients, while the hard and soft pellets withstood different amounts of tensile stress but were made of similar ingredients. The rats were trained similarly in the case of Figure 1, but on the last day of training, either hard or soft pellets were presented in order to eliminate neophobia to the food on the day of microdialysis. As shown in Figure 3, histamine release was significantly increased in rats fed with hard pellets, which is a similar result to Figure 1. By contrast, histamine release was not enhanced in rats fed soft pellets. These observations indicate that the histaminergic activity during feeding is modulated by an oral somatic sensation, but not by blood glucose levels.

\section{LEPTIN AND THE HISTAMINERGIC SYSTEM}

Research of the mechanism of feeding has remarkably progressed by the discovery of the $o b$ gene product, leptin (Zhang et al., 1994). Leptin is a peptide hormone produced and secreted by white adipose tissue, and consequently, its circulating levels are closely related to body fat mass (Frederich et al., 1995; Maffei et al., 1995). Leptin deficiency in mice homozygous for a mutant $o b$ gene ( $o b / o b$ mice) causes obesity, diabetes, and various neuroendocrine anomalies. Among several splice variants of the leptin receptor, the long form of the leptin receptor, which encodes a protein with a longer cytoplasmic domain (OB- $\mathrm{Rb})$, is highly expressed in the central nervous system (Elmquist et al., 1998) and mediates the action of leptin on feeding and energy

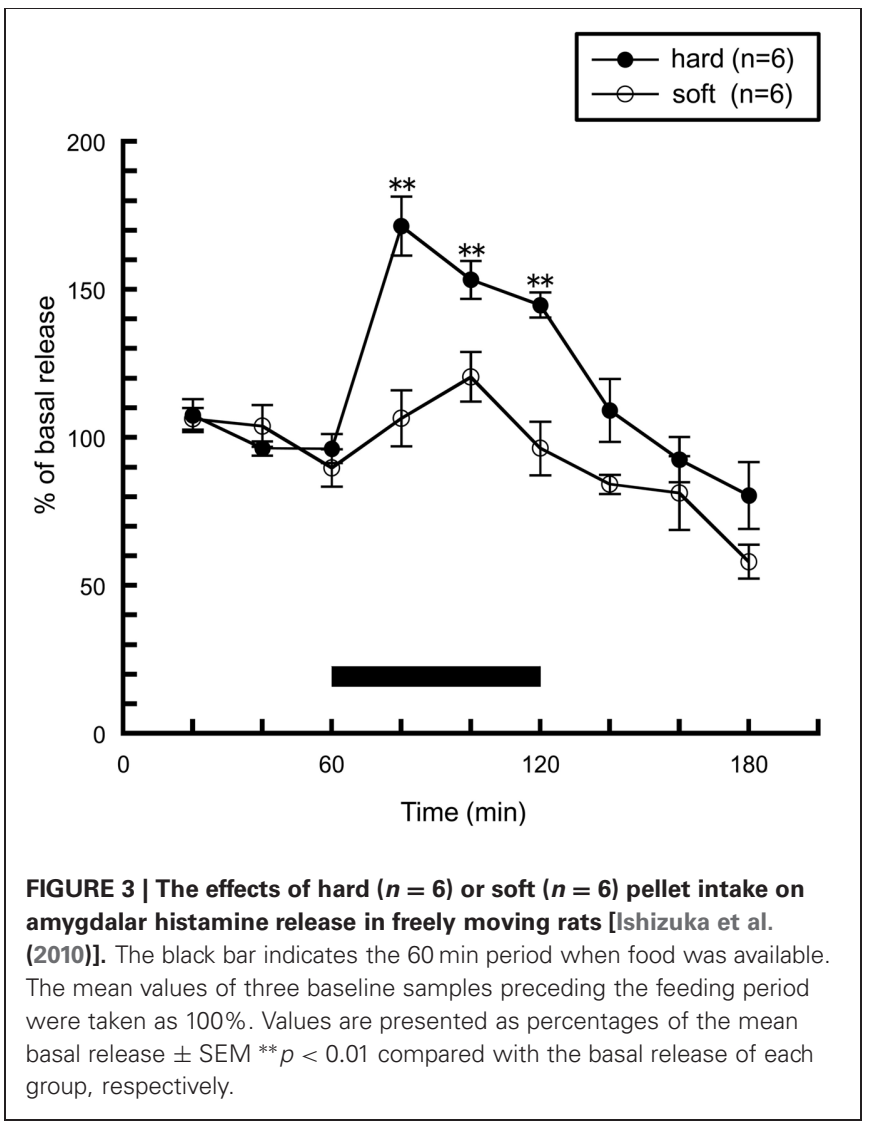


expenditure (Friedman and Halaas, 1998). $d b / d b$ mice, which have a mutation in the $d b$ gene resulting in the abnormal splicing of OB-Rb gene, display a phenotype indistinguishable from $o b / o b$ mice (Chen et al., 1996; Chua et al., 1996). A sufficient number of studies proved that leptin acts in the central nervous system to control feeding (Schwartz et al., 1996; Elmquist et al., 1998), and that leptin is the key molecule which links peripheral adiposity levels to the regulation of energy homeostasis in the brain (Campfield et al., 1995).

The interaction of leptin and the histaminergic system has been well investigated by several researchers, including us. Pretreatment of FMH prior to intraperitoneal leptin administration attenuated leptin-induced suppression of food intake in mice (Morimoto et al., 1999; Yoshimatsu et al., 1999; Toftegaard et al., 2003). Moreover, in histamine $H_{1}$ receptors knockout mice, the effect of leptin was abolished, whereas leptin remarkably reduced food intake in wild type mice (Morimoto et al., 1999; Mollet et al., 2001; Masaki et al., 2001b). Histamine release was shown to significantly increase when leptin was administered intraperitoneally (Morimoto et al., 2000). Combined with these results, leptin may affect feeding behavior through activation of the central histaminergic system via $\mathrm{H}_{1}$ receptors, and the histaminergic system exists downstream of leptin signaling in the control of food intake.

From these findings, activation of the histaminergic system is considered as an effective strategy to treat obesity. Indeed, Masaki et al. (Masaki et al., 2001a) indicated that direct infusion of histamine into the third ventricle prevents the development of obesity in both $d b / d b$ mice and diet-induced obesity (DIO) mice. DIO mice are hyperleptinemic and considered as an analog of human obesity since exogenous leptin cannot improve adiposity. However, given the clinical use of histamine-related compounds in humans, it is essential that pharmacological manipulation should involve peripheral dosing. Although central histamine $\mathrm{H}_{1}$ receptors seem to be a valid and feasible target to control food intake, to date, a selective $\mathrm{H}_{1}$-agonist which can penetrate to the brain and have anti-obesity effect is not available. Therefore, the histamine $\mathrm{H}_{3}$-autoreceptor, the presynaptic receptor which controls histamine synthesis and release, is thought to be a promising target for the control of feeding besides the control of sleep-wake cycle and cognitive disorders as demonstrated before (Passani et al., 2004).

An $\mathrm{H}_{3}$-inverse agonist or antagonist injected peripherally can increase central histaminergic activity, and several studies using animals emphasized the utility of an $\mathrm{H}_{3}$-inverse agonist or antagonist in the regulation of food intake: Intraperitoneal injection of $\mathrm{H}_{3}$-inverse agonist, clobenpropit, could decrease energy intake for $3 \mathrm{~h}$ in DIO mice concomitantly with an increment in hypothalamic histamine release (Ishizuka et al., 2008). In other studies, A-331440, an $\mathrm{H}_{3}$-antagonist, orally administered at $15 \mathrm{mg} / \mathrm{kg}$ for 28 days reduced weight to a level comparable to mice on the low-fat diet (Hancock et al., 2004). Similarly, twice daily oral administration $(20 \mathrm{mg} / \mathrm{kg})$ of the $\mathrm{H}_{3}$-antagonist, NNC 38-1049 (Malmlof et al., 2005) in DIO rats resulted in a sustained reduction in food intake throughout a two week study, and was associated with a significant decrease in body weight compared with controls.

\section{TASTE INFORMATION AND THE HISTAMINERGIC SYSTEM}

Taste is a chemical sensation received from the oral cavity other than a somatic sensation, and it is located between external chemical and internal biochemical environments, and thus its primary role is to distinguish what will or will not be swallowed (Scott and Verhagen, 2000). Taste can be viewed as the entrance of a chemosensory tube that extends through the intestines. Chemical stimulation induces receptor potentials in taste cells, followed by impulses in the taste nerve fibers. Although there is a vast array of chemicals that generate receptor potential in taste cells, physiological and psychological evidence have brought about the classification of the four basic tastes: salty, sweet, bitter, and sour. In addition to these four basic tastes, in increasing number of taste researchers are including "umami" - the unique taste elicited by monosodium glutamate.

We first noticed the possible interaction between taste information and the histaminergic system when we observed histamine release induced by peripheral administration of leptin. As described above, an intraperitoneal injection of leptin facilitated hypothalamic histamine release (Morimoto et al., 2000, Figure 4), however, this enhancement was abolished by a bilateral transection of the chorda tympani (Morimoto-Ishizuka et al., 2001, Figure 4), which is a branch of the facial nerve (seventh cranial nerve) and innervates taste buds in the fungiform papillae on the anterior two-thirds of the tongue and then transports taste information to the central nervous system (Norgren, 1983). In line

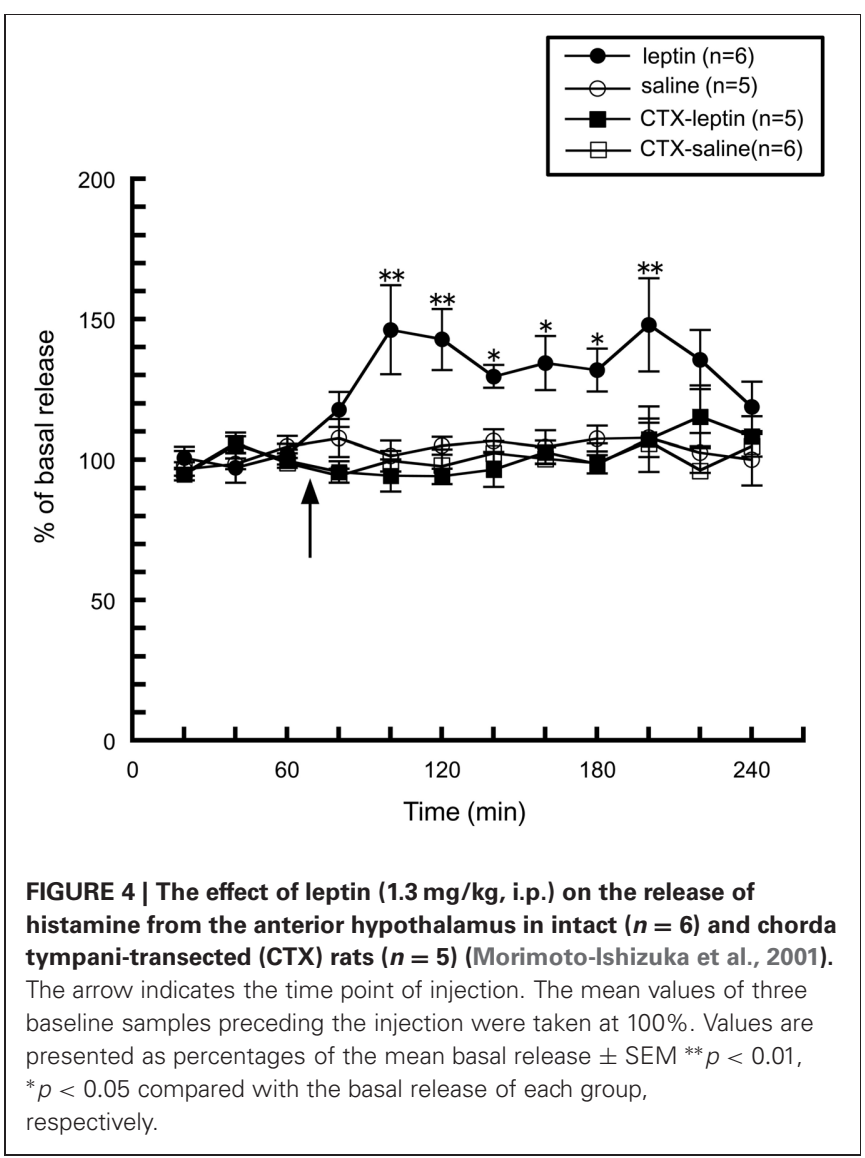


with these observations, an intracerebroventricular injection of leptin had no effect on histamine release (Morimoto-Ishizuka et al., 2001), or the hypothalamic contents of histamine and tele-methylhistamine (Lecklin et al., 2000). Therefore, it is plausible that leptin activates the histaminergic system by peripheral signal inputs via the chorda tympani. These findings led us to study whether direct stimulation of the chorda tympani alters the activity of the histaminergic system.

\section{THE ACTIVATION OF THE HISTAMINERGIC SYSTEM BY TASTE STIMULI VIA THE CHORDA TYMPANI}

Because taste stimulation is a more physiological stimulation than electrical stimulation for the chorda tympani, we investigated the effect of gustatory stimuli on the anterior part of the tongue on hypothalamic histamine release using in vivo microdialysis in urethane-anesthetized rats (Treesukosol et al., 2003). We used five types of taste solution: a four basic taste mixture [composed of $0.1 \mathrm{M} \mathrm{NaCl}$ (salty), $0.5 \mathrm{M}$ sucrose (sweet), $0.02 \mathrm{M}$ quinine $\mathrm{HCl}$ (QHCl, bitter), and $0.01 \mathrm{M} \mathrm{HCl}$ (sour)] and individual solutions of $0.1 \mathrm{M} \mathrm{NaCl}, 0.5 \mathrm{M}$ sucrose, $0.02 \mathrm{M} \mathrm{QHCl}$, and $0.01 \mathrm{M} \mathrm{HCl}$. Each taste solution $(2 \mathrm{ml}$ ) was administered aimed at the anterior tongue directly through the mouth at a rate of $1 \mathrm{ml} / \mathrm{min}$.

The taste stimuli of a four basic taste mixture caused a significant increase in histamine release and this effect was abolished in chorda tympani-transected rats (Figure 5), indicating that taste

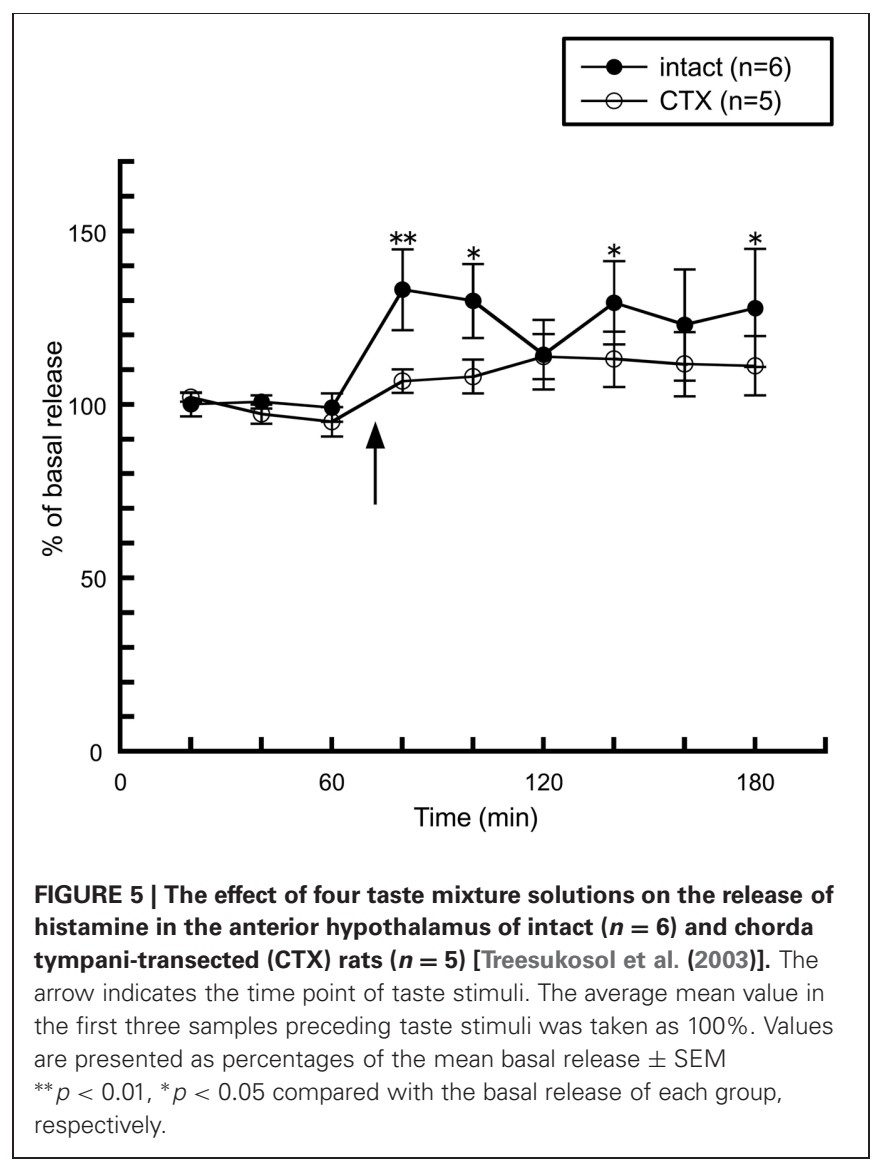

information via the chorda tympani activates the histaminergic system. When each of the components of the four taste mixture was administered separately, a significant increase was observed from administration of $0.1 \mathrm{M} \mathrm{NaCl}$, whereas $0.5 \mathrm{M}$ sucrose and $0.02 \mathrm{M} \mathrm{QHCl}$ showed no significant increase in hypothalamic histamine release (Figure 6A). Although the $\mathrm{HCl}$ solution, $0.01 \mathrm{M}$ $\mathrm{HCl}$, failed to affect histamine release, a higher concentration $(0.03 \mathrm{M})$ increased hypothalamic histamine release (Figure 6B). Distilled water was administered as a control and did not cause any effect on hypothalamic histamine release.

These results can be explained by electrophysiological properties in which the relative magnitude of the chorda tympani response to $0.01 \mathrm{M} \mathrm{HCl}, 0.5 \mathrm{M}$ sucrose, and $0.02 \mathrm{M} \mathrm{QHCl}$ are $0.61,0.21$, and 0.20 , respectively, while the response to $0.1 \mathrm{M}$ $\mathrm{NaCl}$ was 1.0 (Beidler et al., 1955, Table 1). Thus, it was proposed that hypothalamic histamine release may be proportional to the electrophysiological response of the chorda tympani.

\section{THE EFFECT OF TASTE PALATABILITY ON HISTAMINERGIC ACTIVITY}

In the above experiment, we used anesthetized rats in order to stimulate only the region innervated by the chorda tympani, and they did not swallow the taste solution at all. To further investigate the role of the histaminergic system in taste perception, we investigated the effect of taste stimuli on histamine release using freely moving rats (Treesukosol et al., 2005). In this experiment, the taste solution was delivered via an intraoral catheter equipped into the oral cavity beforehand to compare the effects of equal volumes of the solutions ( $5 \mathrm{ml} / 20 \mathrm{~min})$.

Consistent with findings from the above study (Treesukosol et al., 2003), application of $0.1 \mathrm{M} \mathrm{NaCl}$ and $0.01 \mathrm{M} \mathrm{HCl}$ caused significant increases in histamine levels, further supporting the suggestion that this phenomenon is attributed to excitation of the chorda tympani (Figure 7A). On the other hand, in freely moving rats, taste stimuli which did not alter histamine release in anesthetized rats dramatically influenced histamine release: when rats were intraorally infused with $0.001 \mathrm{M} \mathrm{QHCl}$ solution, a significant increase in hypothalamic histamine release was observed (Figure 7B). On the other hand, histamine release was decreased by $0.5 \mathrm{M}$ sucrose and $0.01 \mathrm{M}$ saccharin solutions (Figure 7B). Because both the caloric stimulus sucrose and the non-caloric stimulus saccharin produced a decrease in histamine release, the histamine decrease did not seem to be related to caloric content. In rodent experiments, since chemicals which are described by humans as "bitter" or "nauseous" are rejected by rats and those describe as "sweet" or "pleasurable" by humans are avidly accepted (Scott and Verhagen, 2000), it was postulated that histamine increase is produced by the aversive taste stimuli, but not by palatable tastes. Moreover, these findings suggest the possibility that palatable food blunts histamine release resulting in overeating it.

To clarify this hypothesis, we studied the effect of sweet solutions on hypothalamic histamine release in rats which had acquired aversion to sweet solutions by conditioned taste aversion. Conditioned taste aversion is a gustatory long-term memory established after association of the taste conditioned stimulus (CS) with visceral signals of poisoning unconditioned stimulus (US). After the acquisition of conditioned taste aversion, 


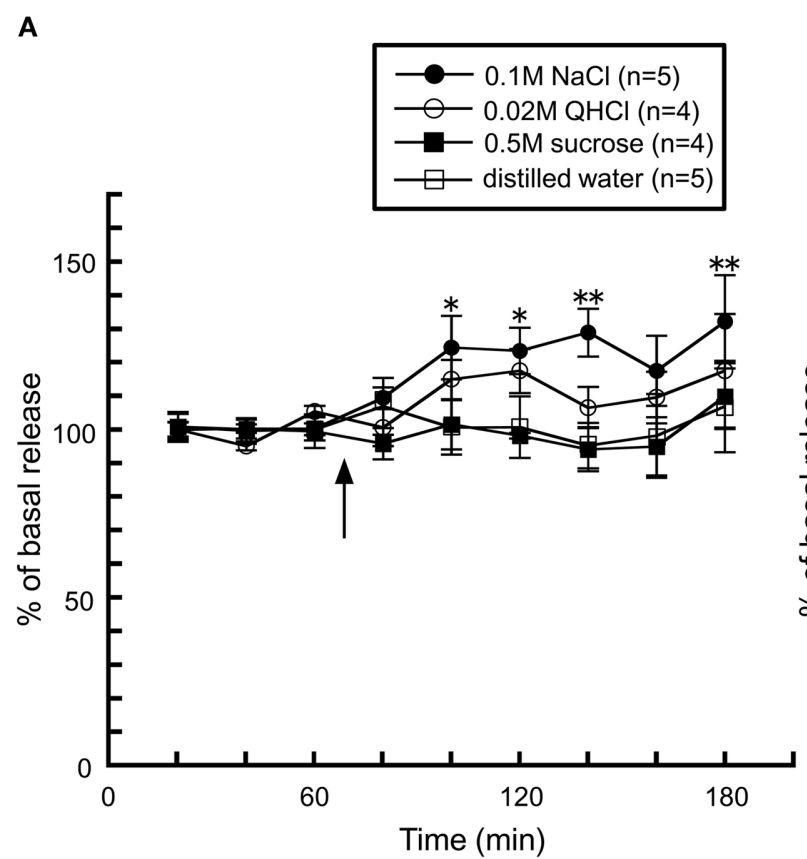

FIGURE 6 | The effects of (A) $0.1 \mathrm{M} \mathrm{NaCl}(n=5), 0.02 \mathrm{M} \mathrm{QHCl}(n=4)$, $0.5 \mathrm{M}$ sucrose $(n=4)$, and distilled water $(n=5)$, and (B) $0.01 \mathrm{M}(n=5)$ and $0.03 \mathrm{M} \mathrm{HCl}(n=4)$ on the release of histamine in the anterior hypothalamus of rats [Treesukosol et al. (2003)]. The arrow indicates the
B

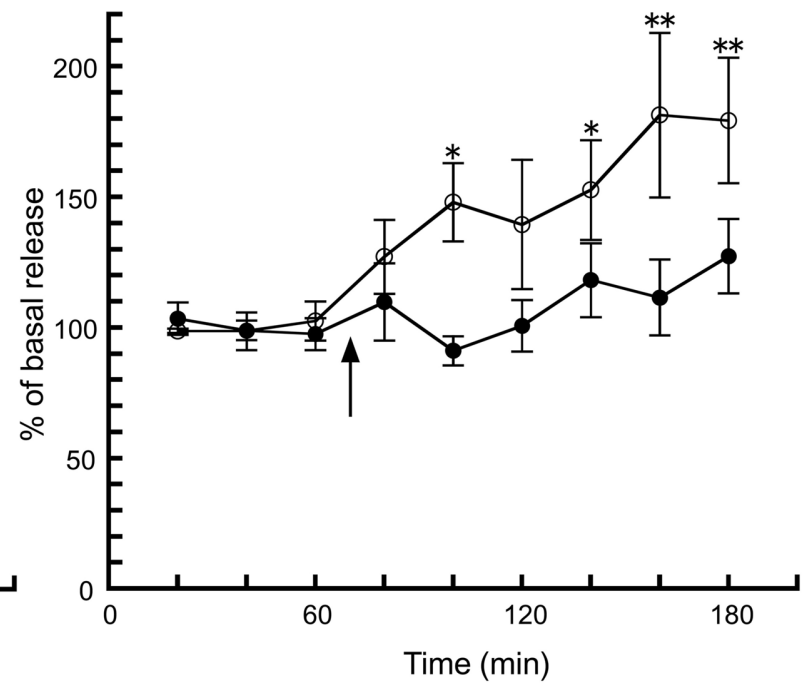

time point of taste stimuli. The mean values of the three baseline samples preceding taste stimuli were taken as $100 \%$. Values are presented as percentages of the mean basal release \pm SEM $^{* *} p<0.01,{ }^{*} p<0.05$ compared with the basal release of each group, respectively.
Table 1 | The relationship between the chorda tympani response and hypothalamic histamine release induced by taste stimuli.

\begin{tabular}{lll}
\hline Taste stimulus & $\begin{array}{l}\text { Relative magnitude } \\
\text { of response }\end{array}$ & $\begin{array}{l}\text { Histamine } \\
\text { release }\end{array}$ \\
\hline $0.1 \mathrm{M} \mathrm{NaCl}$ & 1.0 & + \\
$0.01 \mathrm{M} \mathrm{HCl}$ & 0.61 & $+(0.03 \mathrm{M})$ \\
$0.5 \mathrm{M} \mathrm{sucrose}$ & 0.21 & - \\
$0.02 \mathrm{M} \mathrm{OHCl}$ & 0.20 & - \\
\hline
\end{tabular}

hedonics of the taste CS changes from positive to negative, as indicated by reduced ingestive and increased aversive taste reactivities in response to re-exposures to the CS (Grill and Norgren, 1978).

After rats were conditioned to acquire taste aversion to a sucrose or saccharin solution by one CS (sucrose or saccharin) and US (an intraperitoneal injection of $0.15 \mathrm{M} \mathrm{LiCl}$ ) pairing, reexposure to the CS typically elicited active aversive responses such as gapes and chin rubbing (Grill and Norgren, 1978). In both of the conditioned groups, instead of the histamine decrease seen by the palatable solutions (Figure 7B), both of the CS significantly increased histamine release and the pattern of histamine release was similar to that seen by the $0.001 \mathrm{M} \mathrm{QHCl}$ solution (Figure 8). From these observations, it can be concluded that histaminergic activity is modulated not only by the excitation of the chorda tympani, but also by tastant's palatability.

\section{THE PUTATIVE ROLE OF THE HISTAMINERGIC SYSTEM INDUCED BY AVERSIVE TASTE STIMULI}

In our studies above, we found some key factors which affect histaminergic activity during feeding. They will be divided into two categories: oral sensation conveyed from the oral cavity to the brain (hardness and taste), and emotion elicited by taste perception. Particularly, the histaminergic system showed robust activation by aversive taste stimuli such as $\mathrm{QHCl}$ in naïve rats and the CS in the conditioned rats. What is the physiological role of the histaminergic system under these situations?

Brown et al. hypothesized that the histaminergic system has a role as a danger response system, because the release or turnover of neuronal histamine is enhanced by aversive or dangerous stimuli, such as various kinds of stressors (Brown et al., 2001). More recently, Valdés et al. (2010) expanded their hypothesis and showed that histamine release in the TM is required during motivated behaviors providing the optimal arousal state since the histaminergic system is also known to take part in vigilance (Yamatodani et al., 1996). From this standpoint, it is reasonable to assume that the histaminergic system is promptly activated by aversive or nauseous tastes. Feeding behavior is a complex process which must provide the living organism with a sufficient supply of energy rich edibles as well as certain essential vitamins, minerals, and amino acids from a varied and hazardous external chemical environment. Taste is a very important cue which allows an organism to acquire food selection learning skills, from basic discrimination of edibles from non-edibles to a detailed database of knowledge of a range of foods and their nutritional values or 

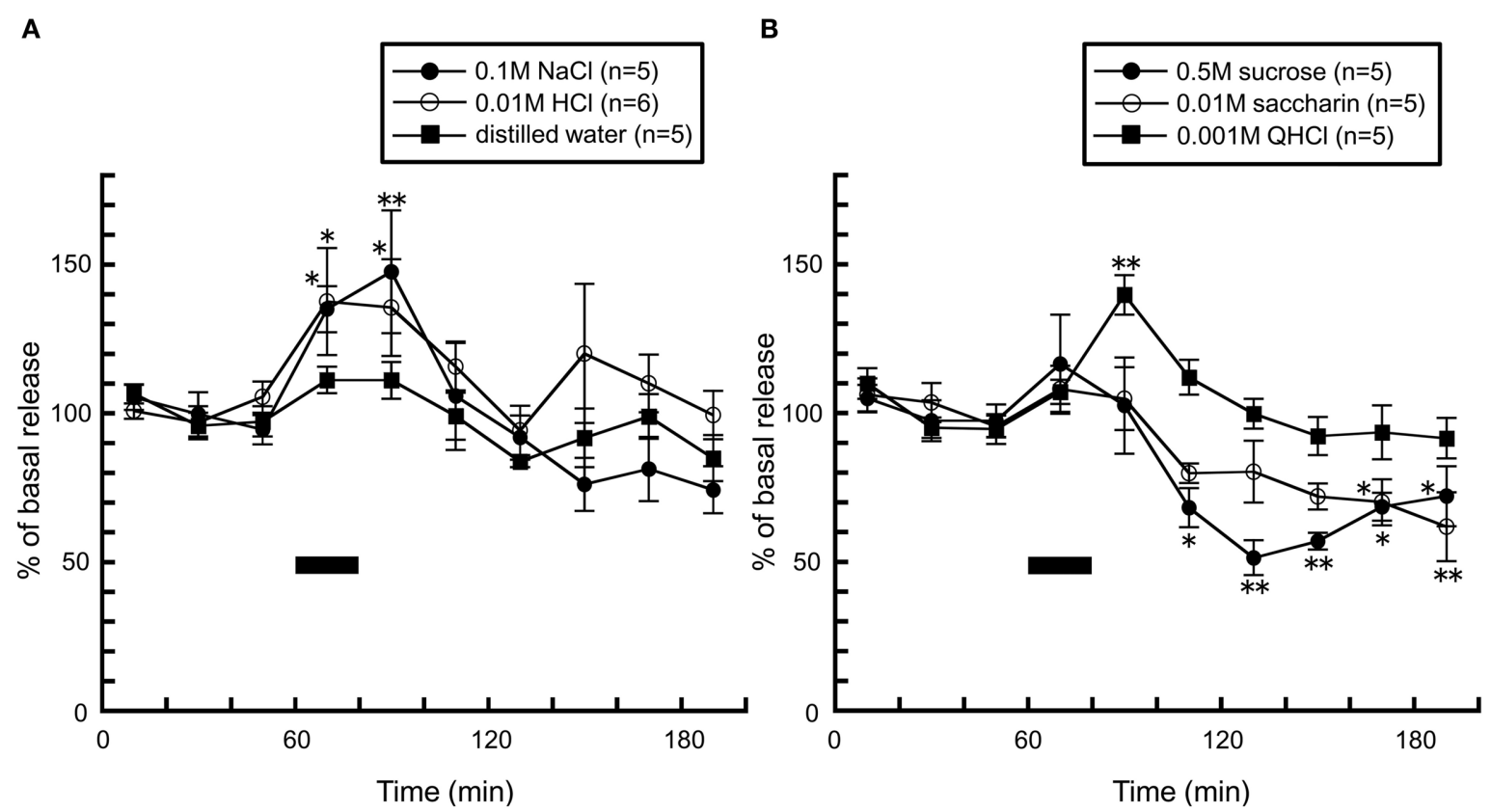

FIGURE 7 | The effect of (A) $0.1 \mathrm{M} \mathrm{NaCl}(n=5), 0.01 \mathrm{M} \mathrm{HCl}(n=6)$, and distilled water $(n=5)$, and (B) $0.001 \mathrm{M} \mathrm{OHCl}(n=5), 0.5 \mathrm{M}$ sucrose $(n=5)$, and $0.01 \mathrm{M}$ saccharin $(n=5)$ on the release of histamine in the anterior hypothalamus of freely moving rats [Treesukosol et al. (2005)]. The black bar indicates the 20 min period

of taste solution infusion. The mean values of the three baseline samples preceding intraoral infusion were taken as $100 \%$. Values are presented as percentages of the mean basal release \pm SEM

${ }^{* *} p<0.01, * p<0.05$ compared with the basal release of each group, respectively.

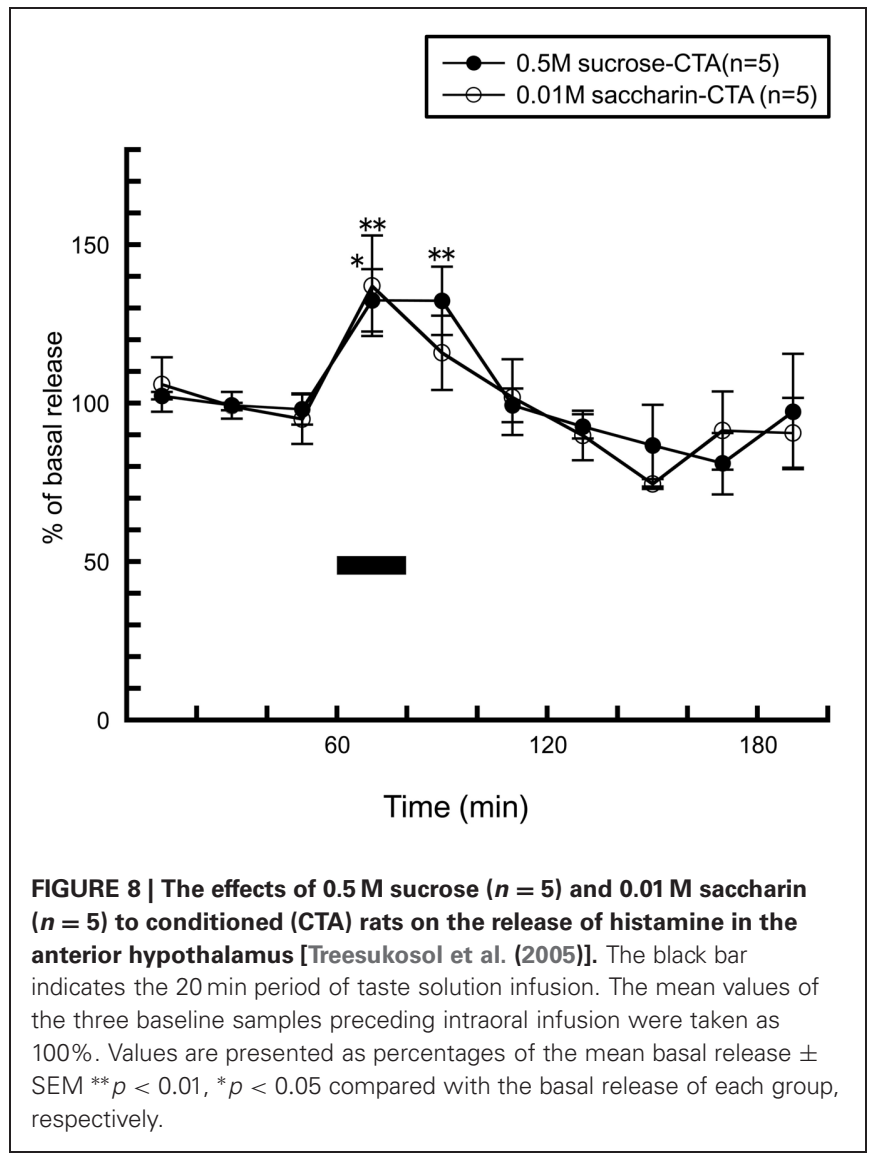

possible toxic effects (Bures et al., 1998). Generally, bitter or aversive taste stimuli mean a substance is harmful for the animals, and they have to reject such substances in order to protect the internal environment as much as possible. Taken together, the histaminergic system may exert a "biowarning system" effect driven by gustatory information resulting in the rejection of taste solution due to an increased arousal level.

\section{CONCLUSION}

The histaminergic system has been shown to be an important neurotransmitter to suppress food intake. Histamine is long considered as a satiety signal, however, recent studies including ours provide new insight into the role of histamine in feeding behavior. The histaminergic system responds to both mechanical and chemical sensory input from the oral cavity and may be exerted as a part of the danger response system. To date, the physiological roles of enhanced histaminergic activity by oral sensation is still unclear, but it is empirically known that the taste or consistency of food affects a variety of aspects of feeding behavior, such as eating speed or jaw movement. Thus, to probe the integrative function of the histaminergic system connecting oral sensory input and these behaviors in detail will be an attractive challenge in the future.

\section{ACKNOWLEDGMENTS}

Parts of the studies in this review were supported by Grant-inAid for Young Scientists (B) from the Ministry of Education, Science, Culture, and Sports of Japan to Tomoko Ishizuka (21791820). 


\section{REFERENCES}

Beidler, L. M., Fishman, I. Y., and Hardiman, C. W. (1955). Species differences in taste responses. Am. J. Physiol. 181, 235-239.

Brown, R. E., Stevens, D. R., and Haas, H. L. (2001). The physiology of brain histamine. Prog. Neurobiol. 63, 637-672.

Bures, J., Bermudez-Rattoni, F., and Yamamoto, T. (1998). Conditioned Taste Aversion: Memory of a Special Kind. Oxford, USA: Oxford University Press.

Campfield, L. A., Smith, F. J., Guisez, Y., Devos, R., and Burn, P. (1995). Recombinant mouse OB protein: evidence for a peripheral signal linking adiposity and central neural networks. Science 269, 546-549.

Chen, H., Charlat, O., Tartaglia, L. A., Woolf, E. A., Weng, X., Ellis, S. J., Lakey, N. D., Culpepper, J., Moore, K. J., Breitbart, R. E., Duyk, G. M., Tepper, R. I., and Morgenstern, J. P. (1996). Evidence that the diabetes gene encodes the leptin receptor: identification of a mutation in the leptin receptor gene in $d b / d b$ mice. Cell 84, 491-495.

Chua, S. C., Chung, W. K., WuPeng, X. S., Zhang, Y., Liu, S. M., Tartaglia, L., and Leibel, R. L. (1996). Phenotypes of mouse diabetes and rat fatty due to mutations in the OB (leptin) receptor. Science 271, 994-996.

Clineschmidt, B. V., and Lotti, V. J. (1973). Histamine: intraventricular injection suppresses ingestive behavior of the cat. Arch. Int. Pharmacodyn. Ther. 206, 288-298.

Coccurello, R., and Moles, A. (2010). Potential mechanisms of atypical antipsychotic-induced metabolic derangement: clues for understanding obesity and novel drug design. Pharmacol. Ther. 127, 210-251.

Deng, C., Weston-Green, K., and Huang, X. F. (2010). The role of histaminergic $\mathrm{H}_{1}$ and $\mathrm{H}_{3}$ receptors in food intake: a mechanism for atypical antipsychotic-induced weight gain? Prog. Neuropsychopharmacol. Biol. Psychiatry 34, 1-4.

Elmquist, J. K., Bjørbaek, C., Ahima, R. S., Flier, J. S., and Saper, C. B. (1998). Distributions of leptin receptor mRNA isoforms in the rat brain. J. Comp. Neurol. 395, 535-547.

Frederich, R. C., Hamann, A., Anderson, S., Löllmann, B., Lowell, B. B., and Flier, J. S. (1995). Leptin levels reflect body lipid content in mice: evidence for diet-induced resistance to leptin action. Nat. Med. 1, 1311-1314.
Friedman, J. M., and Halaas, J. L. (1998). Leptin and the regulation of body weight in mammals. Nature $395,763-770$

Grill, H. J., and Norgren, R. (1978). The taste reactivity test. I. Mimetic responses to gustatory stimuli in neurologically normal rats. Brain Res. 143, 263-279.

Hancock, A. A., Bennani, Y. L., Bush, E. N., Esbenshade, T. A., Faghih, R., Fox, G. B., Jacobson, P., KnourekSegel, V., Krueger, K. M., Nuss, M. E., Pan, J. B., Shapiro, R., Witte, D. G., and Yao, B. B. (2004). Antiobesity effects of A-331440, a novel non-imidazole histamine $\mathrm{H}_{3}$ receptor antagonist. Eur. J. Pharmacol. 487, 183-197.

Inagaki, N., Yamatodani, A., AndoYamamoto, M., Tohyama, M., Watanabe, T., and Wada, H. (1988). Organization of histaminergic fibers in the rat brain. J. Comp. Neurol. 273, 283-300.

Ishizuka, T., Hatano, K., Murotani, T., and Yamatodani, A. (2008). Comparison of the effect of an $\mathrm{H}_{3}$-inverse agonist on energy intake and hypothalamic histamine release in normal mice and leptin resistant mice with high fat diet-induced obesity. Behav. Brain Res. 188, 250-254.

Ishizuka, T., Sako, N., Murotani, T. Morimoto, A., Yamatodani, A., and Ohura, K. (2010). The effect of hardness of food on amygdalar histamine release in rats. Brain Res. 1313, 97-102.

Itoh, Y., Oishi, R., and Saeki, K. (1991). Feeding-induced increase in the extracellular concentration of histamine in rat hypothalamus as measured by in vivo microdialysis. Neurosci. Lett. 125, 235-237.

Itowi, N., Nagai, K., Nakagawa, H., Watanabe, T., and Wada, H. (1988). Changes in the feeding behavior of rats elicited by histamine infusion. Physiol. Behav. 44, 221-226.

Kalucy, R. S. (1980). Drug-induced weight gain. Drugs 19, 268-278.

Kim, S. F., Huang, A. S., Snowman, A. M., Teuscher, C., and Snyder, S. H. (2007). From the Cover: antipsychotic drug-induced weight gain mediated by histamine $\mathrm{H}_{1}$ receptorlinked activation of hypothalamic AMP-kinase. Proc. Natl. Acad. Sci. U.S.A. 104, 3456-3459.

Lecklin, A., Etu-Seppälä, P., Stark, H., and Tuomisto, L. (1998). Effects of intracerebroventricularly infused histamine and selective $\mathrm{H}_{1}, \mathrm{H}_{2}$ and $\mathrm{H}_{3}$ agonists on food and water intake and urine flow in Wistar rats. Brain Res. 793, 279-288.
Lecklin, A., Hermonen, P., Tarhanen, J., and Männistö, P. T. (2000). An acute i.c.v. infusion of leptin has no effect on hypothalamic histamine and tele-methylhistamine contents in Wistar rats. Eur. J. Pharmacol. 395, 113-119.

Lecklin, A., and Tuomisto, L. (1998) The blockade of $\mathrm{H}_{1}$ receptors attenuates the suppression of feeding and diuresis induced by inhibition of histamine catabolism. Pharmacol. Biochem. Behav. 59, 753-758.

Lecklin, A., Tuomisto, L., and MacDonald, E. (1995). Metoprine, an inhibitor of histamine $\mathrm{N}$ methyltransferase but not catechol-O-methyltransferase, suppresses feeding in sated and in food deprived rats. Methods Find. Exp. Clin. Pharmacol. 17, 47-52.

Maffei, M., Halaas, J., Ravussin, E. Pratley, R. E., Lee, G. H., Zhang, Y., Fei, H., Kim, S., Lallone, R., and Ranganathan, S. (1995). Leptin levels in human and rodent: measurement of plasma leptin and $o b$ RNA in obese and weight-reduced subjects. Nat. Med. 1, 1155-1161.

Malmlof, K., Zaragoza, F. Golozoubova, V., Refsgaard, H. H., Cremers, T., Raun, K., Wulff, B. S., Johansen, P. B., Westerink, B., and Rimvall, K. (2005). Influence of a selective histamine $\mathrm{H}_{3}$ receptor antagonist on hypothalamic neural activity, food intake and body weight. Int. J. Obes. (Lond.) 29, 1402-1412.

Masaki, T., Yoshimatsu, H., Chiba S., Watanabe, T., and Sakata, T. (2001a). Central infusion of histamine reduces fat accumulation and upregulates UCP family in leptin-resistant obese mice. Diabetes 50, 376-384.

Masaki, T., Yoshimatsu, H., Chiba, S., Watanabe, T., and Sakata, T. (2001b). Targeted disruption of histamine $\mathrm{H}_{1}$-receptor attenuates regulatory effects of leptin on feeding, adiposity, and UCP family in mice. Diabetes 50, 385-391.

Mollet, A., Lutz, T. A., Meier, S. Riediger, T., Rushing, P. A., and Scharrer, E. (2001). Histamine $\mathrm{H}_{1}$ receptors mediate the anorectic action of the pancreatic hormone amylin. Am. J. Physiol. Regul. Integr. Comp. Physiol. 281, R1442-R1448.

Morimoto-Ishizuka, T., Yamamoto, Y., and Yamatodani, A. (2001). The role of the chorda tympani nerve in the activation of the rat hypothalamic histaminergic system by leptin. Neurosci. Lett. 300, 107-110.

Morimoto, T., Yamamoto, Y., Mobarakeh, J. I., Yanai, K. Watanabe, T., Watanabe, T. and Yamatodani, A. (1999). Involvement of the histaminergic system in leptin-induced suppression of food intake. Physiol. Behav. 67, 679-683.

Morimoto, T., Yamamoto, Y., and Yamatodani, A. (2000). Leptin facilitates histamine release from the hypothalamus in rats. Brain Res. 868, 367-369.

Norgren, R. (1983). The gustatory system in mammals. Am. J. Otolaryngol. 4, 234-237.

Ookuma, K., Sakata, T., and Fujimoto, K. (1990). Evidence for feeding elicited through antihistaminergic effects of tricyclic antidepressants in the rat hypothalamus. Psychopharmacology (Berl.) 101, 481-485.

Ookuma, K., Sakata, T., Fukagawa, K., Yoshimatsu, H., Kurokawa, M., Machidori, H., and Fujimoto, K. (1993). Neuronal histamine in the hypothalamus suppresses food intake in rats. Brain Res. 628, 235-242.

Oomura, Y., Ooyama, H., Yamamoto, T., Naka, F., Kobayashi, N., and Ono, T. (1967). Neuronal mechanism of feeding. Prog. Brain Res. 27, 1-33.

Orthen-Gambill, N. (1988). Antihistaminic drugs increase feeding, while histidine suppresses feeding in rats. Pharmacol. Biochem. Behav. 31, 81-86.

Orthen-Gambill, N., and Salomon, M. (1990). Differential effects of psychotropic drugs on feeding in rats: is histamine blockade involved? Pharmacol. Biochem. Behav. 36, 837-841.

Orthen-Gambill, N., and Salomon, M. (1992). FMH-induced decrease in central histamine levels produces increased feeding and body weight in rats. Physiol. Behav. 51, 891-893.

Panula, P., Yang, H. Y., and Costa, E. (1984). Histamine-containing neurons in the rat hypothalamus. Proc. Natl. Acad. Sci. U.S.A. 81, 2572-2576.

Passani, M. B., Lin, J. S., Hancock, A., Crochet, S., and Blandina, P. (2004). The histamine $\mathrm{H}_{3}$ receptor as a novel therapeutic target for cognitive and sleep disorders. Trends Pharmacol. Sci. 25, 618-625.

Russ, M. J., and Ackerman, S. H. (1988). Antidepressants and weight gain. Appetite 10, 103-117.

Sakata, T., Ookuma, K., Fukagawa, K., Fujimoto, K., Yoshimatsu, H., Shiraishi, T., and Wada, H. (1988). Blockade of the histamine $\mathrm{H}_{1}$ receptor in the rat ventromedial hypothalamus and feeding elicitation. Brain Res. 441, 403-407. 
Saper, C. B., Chou, T. C., and Elmquist, J. K. (2002). The need to feed: homeostatic and hedonic control of eating. Neuron 36, 199-211.

Schwartz, M. W., Seeley, R. J., Campfield, L. A., Burn, P., and Baskin, D. G. (1996). Identification of targets of leptin action in rat hypothalamus. J. Clin. Invest. 98, 1101-1106.

Scott, T. R., and Verhagen, J. V. (2000). Taste as a factor in the management of nutrition. Nutrition 16, 874-885.

Sheiner, J. B., Morris, P., and Anderson, G. H. (1985). Food intake suppression by histidine. Pharmacol. Biochem. Behav. 23, 721-726.

Toftegaard, C. L., Knigge, U., Kjaer, A., and Warberg, J. (2003). The role of hypothalamic histamine in leptininduced suppression of short-term food intake in fasted rats. Regul. Pept. 111, 83-90.

Treesukosol, Y., Ishizuka, T., Yamamoto, C., Senda, K., Tsutsumi, S., Yamatodani, A., and Yamamoto, T. (2005). Hypothalamic histamine release by taste stimuli in freely moving rats: possible implication of palatability. Behav. Brain Res. 164, 67-72.
Treesukosol, Y., Ishizuka, T., Yamamoto, T., and Yamatodani, A. (2003). The effect of taste stimuli on histamine release in the anterior hypothalamus of rats. Brain Res. 964, 51-55.

Tuomisto, L., Yamatodani, A., Jolkkonen, J., Sainio, E. L., and Airaksinen, M. M. (1994). Inhibition of brain histamine synthesis increases food intake and attenuates vasopressin response to salt loading in rats. Methods Find. Exp. Clin. Pharmacol. 16, 355-359.

Valdés, J. L., Sánchez, C., Riveros, M. E., Blandina, P., Contreras, M., Farías, P., and Torrealba, F. (2010). The histaminergic tuberomammillary nucleus is critical for motivated arousal. Eur. J. Neurosci. 31, 2073-2085.

Vaziri, P., Dang, K., and Anderson, G. H. (1997). Evidence for histamine involvement in the effect of histidine loads on food and water intake in rats. J. Nutr. 127, 1519-1526.

Watanabe, T., Taguchi, Y., Shiosaka, S., Tanaka, J., Kubota, H., Terano, Y., Tohyama, M., and Wada, H. (1984). Distribution of the histaminergic neuron system in the central nervous system of rats; a fluorescent immunohistochemical analysis with histidine decarboxylase as a marker. Brain Res. 295, 13-25.

Watanabe, T., Yamatodani, A., Maeyama, K., and Wada, H. (1990). Pharmacology of $\alpha$ fluoromethylhistidine, a specific inhibitor of histidine decarboxylase. Trends Pharmacol. Sci. 11, 363-367.

Yamatodani, A., Mochizuki, T., and Mammoto, T. (1996). New vistas on histamine arousal hypothesis: microdialysis studies. Methods Find. Exp. Clin. Pharmacol. 18, 113-117.

Yoshimatsu, H., Chiba, S., Tajima, D. Akehi, Y., and Sakata, T. (2002). Histidine suppresses food intake through its conversion into neuronal histamine. Exp. Biol. Med. (Maywood) 227, 63-68.

Yoshimatsu, H., Itateyama, E., Kondou, S., Tajima, D., Himeno, K., Hidaka, S., Kurokawa, M., and Sakata, T. (1999). Hypothalamic neuronal histamine as a target of leptin in feeding behavior. Diabetes 48, 2286-2291.

Zhang, Y., Proenca, R., Maffei, M., Barone, M., Leopold, L., and
Friedman, J. M. (1994). Positional cloning of the mouse obese gene and its human homologue. Nature 372, 425-432.

Conflict of Interest Statement: The authors declare that the research was conducted in the absence of any commercial or financial relationships that could be construed as a potential conflict of interest.

Received: 10 January 2012; accepted: 08 May 2012; published online: 24 May 2012.

Citation: Ishizuka T and Yamatodani A (2012) Integrative role of the histaminergic system in feeding and taste perception. Front. Syst. Neurosci. 6:44. doi: 10.3389/fnsys.2012.00044

Copyright (c) 2012 Ishizuka and Yamatodani. This is an open-access article distributed under the terms of the Creative Commons Attribution Non Commercial License, which permits non-commercial use, distribution, and reproduction in other forums, provided the original authors and source are credited. 